\title{
A Novel Polycationic Analogue of Gratisin with Antibiotic Activity against both Gram-positive and Gram-negative Bacteria
}

\author{
Makoto Tamaki, Manabu Kokuno, Yumiko Suzuki, Mitsuko Iwama, Mitsuno Shindo, \\ Yoshiki Uchida
}

Received: November 1, 2007 / Accepted: December 27, 2007

(C) Japan Antibiotics Research Association

\begin{abstract}
A novel polycationic analogue of gratisin, cyclo(-Val-Orn-Leu-D-Phe-Pro-D-Lys-) ${ }_{2}$, was designed and synthesized, which exhibited strong activity against all Gram-positive and Gram-negative bacteria tested. Its activity against Pseudomonas aeruginosa IFO 3080 was two times higher than gramicidin $\mathrm{S}$.
\end{abstract}

Keywords polycationic analogue, gratisin, cyclododecapeptide antibiotic, Gram-positive and Gram-negative bacteria, circular dichroism

Gratisin (GR), cyclo(-Val ${ }^{1}-\mathrm{Orn}^{2}-\mathrm{Leu}^{3}$-D-Phe $\left.{ }^{4}-\mathrm{Pro}^{5}-\mathrm{D}-\mathrm{Tyr}^{6}-\right)_{2}$ [1 3], is a potent cyclopeptide antibiotic isolated from Bacillus brevis Y-33. It has been proposed that the principal modes of antibiotic actions result from an interaction of GR with the cell membrane of the target bacteria. GR then adopts an antiparallel $\beta$-sheet conformation, which disrupts cell membrane [3]. So far, no resistance has been found for the antibiotic, because it requires significant alteration of the lipid composition of the cell membrane [4]. In view of widespread antibiotic resistance that has become a serious threat to public health, amphiphilic antibiotics are attractive targets for drug discovery. However, in contrast to the strong activity against Gram-positive bacteria, GR is inactive against Gram-negative bacteria. On the other hand, polycationic analogues of gramicidin S (GS), which is also an amphiphilic membrance-active cyclic decapeptide, cyclo(-Val $\left.{ }^{1}-\mathrm{Orn}^{2}-\mathrm{Leu}^{3}-\mathrm{D}-\mathrm{Phe}^{4}-\mathrm{Pro}^{5}-\right)_{2}$, are strongly active against both Gram-positive and Gram-negative bacteria, and its polycationic nature is considered to be responsible for the antibacterial activity [5]. It has been shown that polycationic analogues efficiently permeabilize the outer membrance of Gram-negative bacteria. Therefore, we planed to synthesize GR analogues that possess additional amino acid residues with amino group side chain, expecting the polycationic GR analogues to be active against both Gram-positive and Gram-negative bacteria.

In the present account, we designed and synthesized a novel GR analogue, cyclo(-Val-Orn-Leu-D-Phe-Pro-DLys- $)_{2}(\mathbf{1})$, which has D-Lys ${ }^{6,6^{\prime}}$ residues in place of D-Tyr ${ }^{6,6^{\prime}}$ residues. We selected $\mathrm{D}-\mathrm{Tyr}^{6,6^{\prime}}$ residues as the replacement sites of D-Lys residues, because [D-Phe $\left.{ }^{6,6^{\prime}}\right]$-GR and [D$\left.\mathrm{Ala}^{6,6^{\prime}}\right]$-GR possess similar antimicrobial activity and secondary structure to that of parent GR $[1,2]$.

Synthesis of 1 was performed by a solid-phase method using oxime resin [6]. The homogeneity of $\mathbf{1}$ was confirmed by thin-layer chromatography, high performance liquid chromatography, elemental analysis, and fast-atom bombardment mass spectrometry.

The antibiotic activities of 1, GR and GS are summarized in Table 1. 1 showed the same antimicrobial activity as that of GR against all Gram-positive bacteria
M. Tamaki (Corresponding author), M. Kokuno, Y. Suzuki, M. Iwama: Department of Chemistry, Toho University, Funabashi, Chiba 274-8510, Japan, E-mail: tamaki@chem.sci.toho-u.ac.jp
M. Shindo, Y. Uchida: Department of Food Science and Nutrition, Osaka Shoin Women's University, Higashi-Osaka, Osaka 577-8550, Japan 
Table 1 Antibiotic activities of gramicidin S (GS), gratisin (GR) and $\mathbf{1}^{\text {a) }}$

\begin{tabular}{lccc}
\hline & \multicolumn{3}{c}{ MIC $(\mu \mathrm{g} / \mathrm{ml})$} \\
\cline { 2 - 4 } Test organisms & GS & GR & $\mathbf{1}$ \\
\hline Bacillus subtilis IFO 3513 & 3.13 & 6.25 & 6.25 \\
Bacillus megaterium ATCC 19213 & 3.13 & 6.25 & 6.25 \\
Staphylococcus epidermidis IFO 12933 & 3.13 & 6.25 & 6.25 \\
Staphylococcus aureus IFO 12732 & 3.13 & 6.25 & 6.25 \\
Escherichia coli IFO 12734 & 25 & 100 & 25 \\
Pseudomonas aeruginosa IFO 3080 & 25 & 100 & 12.5 \\
\hline
\end{tabular}

a) $\mathrm{MIC}(\mu \mathrm{g} / \mathrm{ml})$ was determined by a microplate dilution method with $10^{6}$ organisms per milliliter.

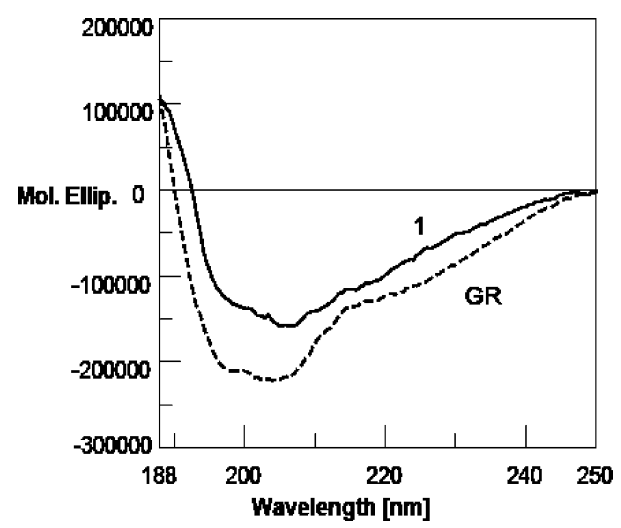

Fig. 1 CD spectra of cyclo(-Val-Orn-Leu-D-Phe-Pro-D-Lys-) (1) and gratisin (GR) in $\mathrm{MeOH}$.

tested. In addition, $\mathbf{1}$ showed strong activity against Gramnegative bacteria; its activity against Pseudomonas aeruginosa IFO 3080 is two times higher than GS. Thus, $\mathbf{1}$ exhibited considerable antimicirobial activity against both Gram-positive and Gram-negative bacteria, although the hydrophobic - hydrophilic balance of the parent GR was no longer retained in $\mathbf{1}$.

To investigate the structure-activity relationship of $\mathbf{1}, \mathrm{CD}$ spectra of 1 and GR were measured in $\mathrm{MeOH}$. In the $\mathrm{CD}$ spectrum of 1 a curve similar to that of GR was observed, but with weaker intensity (Fig. 1). The results indicate that the conformation of $\mathbf{1}$ is similar to that of GR, but the conformation was distorted or destabilized compared with the parent GR. The CD spectra reflect the stability of the secondary structure of GR and GR analogues, which is usually related to their antimicrobial activity against Grampositive bacteria $[1,2]$. However, a good correlation between the $\mathrm{CD}$ spectra and antimicrobial activity for polycationic 1 could not be found.
Thus, $\mathbf{1}$ is the first example of GR analogue with strong activities against both Gram-positive and Gram-negative bacteria. Currently, we are investigating the design and synthesis of other amphiphilic cyclopeptides with strong activities against both Gram-positive and Gram-negative bacteria on the basis of the present studies.

\section{Experimental}

Melting points were measured on Mel-Temp II melting point apparatus (Laboratory Devices USA) and are uncorrected. Low-resolution mass spectra (LR-MS) were obtained by using FAB-MS on a JEOL600H mass spectrometer. CD spectra were recorded on a Jasco J-820 spectropolarimeter using a quarts cell of $0.5 \mathrm{~mm}$ pathlength. The $\mathrm{CD}$ spectra in $\mathrm{MeOH}$ were measured at a peptide concentration of $1.10 \times 10^{-4} \mathrm{M}$ at room temperature.

\section{Cyclo(-Val-Orn-Leu-D-Phe-Pro-D-Lys-) $)_{2} \cdot \mathbf{4 H B r}(1)$}

A protected linear precursor oxime, H-D-Phe-Pro-D-Lys(Z)Val-Orn(Z)-Leu-D-Phe-Pro-D-Lys(Z)-Val-Orn(Z)-Leuoxime (Z-=bennzyloxycarbonyl-), was prepared by using Boc-solid phase peptide synthesis on resin (Loading of oxime group: $0.35 \mathrm{mmol} / \mathrm{g}$ resins). The formation of the cyclic peptide by the cyclization-cleavage of H-D-Phe-ProD-Lys(Z)-Val-Orn(Z)-Leu-D-Phe-Pro-D-Lys(Z)-Val-Orn(Z)Leu- oxime on resin was performed in 1,4-dioxane with 2 equivalents of triethylamine and acetic acid for 1 day at room temperature [6]. The cyclizations gave cyclo[-Val$\operatorname{Orn}(Z)-L e u-D-P h e-P r o-D-L y s(Z)-]_{2}$ in yield of $51 \%$. The removal of all the masking groups by $25 \% \mathrm{HBr} /$ acetic acid yielded 1.

Mp 211 213 ${ }^{\circ} \mathrm{C}$. Found: C 48.28, H 7.39, N 12.25\%. Calcd for $\mathrm{C}_{72} \mathrm{H}_{116} \mathrm{~N}_{16} \mathrm{O}_{12} \cdot 4 \mathrm{HBr} \cdot 4 \mathrm{H}_{2} \mathrm{O}: \mathrm{C} 48.22, \mathrm{H} 7.19, \mathrm{~N}$ $12.50 \%$. LR-FAB-MS (matrix: m-NBA): $\mathrm{m} / z$ $[\mathrm{M}+\mathrm{H}]^{+}$.

\section{References}

1. Waki M, Izumiya N. "Biochemistry of Peptide Antibiotics" ed. by Kleinkauf, H. and Dhren, H. Von., de Gruyter, Berlin, Fed Rep, Ger., pp. 205-244 (1990)

2. Tamaki M. Studies on peptide antibiotic "gratisin". Bull Chem Soc Jpn 57: 3210-3220 (1982)

3. Watanabe E, Sakamoto Y, Kikuchi S, Tamaki M. Conformational analysis of peptide antibiotic "gratisin" "Peptide Science 2005" ed. by Wakamiya, pp. 227-230 (2006) 
4. Hancock REW. Peptide antibiotics. Lancet 349: 418-422 (1997)

5. Ando S, Nishikawa H, Takiguchi H, Lee S, Sugihara G. Antimicrobial specificity and hemolytic activity of cyclized basic amphiphilic $\beta$-structural model peptides and their interactions with phospholipid bilayers. Biochim Biophys
Acta 1147: 42-49 (1993)

6. Tamaki M, Honda K, Kikuchi S, Ishii R. Biomimetic formation of gramicidin $\mathrm{S}$ by dimerization-cyclization pentapeptide precursor on solid support. Tetrahedron Lett 47(48): 8475-8478 (2006) 